\title{
The Developing Scene: Ten-year Review of a Psychiatric Hospital Population
}

\author{
D. F. EARLY, M. NICHOLAS
}

British Medical fournal, 1971, 4, 793-795

An initial survey was carried out in Glenside Hospital in 1960 because it was felt that "a large proportion of all patients under care in mental hospitals show no serious disturbance of behaviour, and their retention is determined largely by social factors." "That survey was followed four years later by a similar review, ${ }^{2}$ which recommended a precise overall national plan for the future of mental hospitals with local planning in consultation with individual hospitals. The present paper reports the situation in 1970 .

\section{Method and Results}

The method used was similar to that of the 1960 and 1964 surveys; patients who had been resident in the hospital for three months or longer were reviewed and a questionnaire was completed. The information was then transferred to punch cards for analysis. This method was used on this occasion because of the difficulty in obtaining computer time.

In 19601,012 patients ( 559 females, 453 males) were reviewed and in 1964948 patients (514 females, 434 males). Altogether 452 of these patients (223 females, 229 males) remained in hospital in 1970. Since the 1964 survey 305 patients (200 females, 105 males) had died and 191 had been discharged. At the time of the present survey there were 287 patients who had been in hospital three months or longer in addition to the population remaining from 1964. The population surveyed was therefore 739-a reduction of 219 since 1964 and of 273 since 1960 - that is, a fall of $26.9 \%$ in 10 years (females $163,29.1 \%$; males $110,24 \cdot 3 \%$ ).

\section{Glenside Hospital, Bristol}

D. F. EARLY, D.P.H., D.P.M., Consultant Psychiatrist

M. NICHOLAS, M.R.C.P., D.P.M., Consultant Psychiatrist

Age and Sex Distribution.-No patient under 20 had been in hospital three months or more. Twenty-two patients (13 males, 9 females) were aged 20-29 years and 42 (24 male,18 female) were aged 30-39 years. The proportion of the total population over the age of 65 had risen from $33.8 \%$ (342 patients) in 1960 to $41.9 \%$ (310 patients) in 1970 (Table I). There were 215 patients (54 males, 161 females) over the age of 70 -that is, $30 \%$ of the population reviewed $(40 \%$ in the case of women)-and 77 patients ( 13 males, 64 females) over the age of $80-10.6 \%$ of the total.

TABLE I-Age and Sex Ratio

\begin{tabular}{|c|c|c|c|c|c|c|c|c|c|c|c|c|}
\hline \multirow{3}{*}{ Year } & \multicolumn{4}{|c|}{ Male } & \multicolumn{4}{|c|}{ Female } & \multicolumn{4}{|c|}{ Total } \\
\hline & \multicolumn{2}{|c|}{ Under 65} & \multicolumn{2}{|c|}{ Over 65} & \multicolumn{2}{|c|}{ Under 65} & \multicolumn{2}{|c|}{ Over 65} & \multicolumn{2}{|c|}{ Under 65} & \multicolumn{2}{|c|}{ Over 65} \\
\hline & No. & ${ }_{0}^{\circ}$ & No. & $\%$ & No. & $\%$ & No. & $\%$ & No. & $\%$ & No. & $\%$ \\
\hline $\begin{array}{l}1960 \\
1964 \\
1970\end{array}$ & $\begin{array}{l}354 \\
320 \\
255\end{array}$ & $\begin{array}{l}78 \cdot 1 \\
73 \cdot 8 \\
74 \cdot 3\end{array}$ & $\begin{array}{r}99 \\
114 \\
88\end{array}$ & $\begin{array}{l}21 \cdot 8 \\
26 \cdot 2 \\
25 \cdot 7\end{array}$ & $\begin{array}{l}316 \\
273 \\
174\end{array}$ & $\begin{array}{l}56 \cdot 5 \\
53 \cdot 1 \\
44 \cdot 0\end{array}$ & $\begin{array}{l}243 \\
241 \\
222\end{array}$ & \begin{tabular}{|l|}
43.4 \\
46.8 \\
$56 \cdot 0$
\end{tabular} & $\begin{array}{l}670 \\
593 \\
429\end{array}$ & $\begin{array}{l}66 \cdot 2 \\
62 \cdot 6 \\
58 \cdot 1\end{array}$ & $\begin{array}{l}342 \\
355 \\
310\end{array}$ & $\begin{array}{l}33.8 \\
37.4 \\
41.9\end{array}$ \\
\hline
\end{tabular}

Patient Status.-The number of detained patients had fallen since 1960 though the proportion had changed little-in 1960,52 patients $(5 \cdot 1 \%)$; in 1964,53 patients $(5.6 \%)$; and in 1970,41 patients $(5.5 \%)$.

Criminal Acts.-The number of patients with a history of criminal acts had fallen from $38(3.7 \%)$ in 1960 and 50 $(5.3 \%)$ in 1964 to $19(2.6 \%)$ in 1970 .

Duration of Stay.-The number of patients who in 1970 had spent five years or more in hospital was 273 fewer than in 1960 and the proportion of these had fallen appreciably (Table II)-from $72.8 \%$ to $59 \cdot 8 \%$. Of the patients who stayed two to five years there were 125 in 1960, 136 in 1964, and 126 in 1970. The number had not increased but the proportion of these patients had gone up from $12 \cdot 3 \%$ to $17 \%$ in 10 years. 
TABLE II-Duration of Stay

\begin{tabular}{|c|c|c|c|c|}
\hline & & 1960 & 1964 & 1970 \\
\hline $\begin{array}{l}5 \text { years }+\ldots \\
2 \text { years }+. . \\
\text { 3-24 months } \\
\text { Less than } 3 \text { months }\end{array}$ & $\begin{array}{l}\cdots \\
\cdots \\
\cdots\end{array}$ & $\begin{array}{l}737(72 \cdot 8 \%) \\
862(85 \cdot 2 \%) \\
150 \\
135\end{array}$ & $\begin{array}{l}672\left(70 \cdot 8^{\circ}{ }^{\circ}\right) \\
808\left(85 \cdot 2^{\circ}\right) \\
140 \\
131\end{array}$ & $\begin{array}{l}500(59 \cdot 8 \%) \\
626(74.5 \%) \\
113 \text { (approx.) } \\
121 \text { (appor }\end{array}$ \\
\hline Total No. of patients & . & 1,447 & 1,079 & 860 \\
\hline
\end{tabular}

Behaviour.-Antisocial behaviour was shown by 142 patients (73 males, 69 females); 597 (80.6\%; 270 males, 396 females) showed no such traits or exhibited them mildly. This compares with $84.4 \%$ in 1960 and $83 \%$ in 1964 . By comparison the social participation of 516 patients $(69.8 \% ; 211$ males, 305 females) was regarded as poor or bad.

Nursing Care and Supervision.-There was a fall in the number and proportion of patients thought not to require nursing care and a slight fall in the number requiring minimal nursing (Table III).

TABLE III-Nursing Care and Supervision

\begin{tabular}{|c|c|c|c|}
\hline & 1960 & 1964 & 1970 \\
\hline $\begin{array}{l}\text { Nursing care not necessary } \\
\text { Minimal nursing } \ldots\end{array}$ & $\begin{array}{l}122(12 \cdot 0 \%) \\
355(35.0 \%)\end{array}$ & $\begin{array}{l}169(17 \cdot 8 \%) \\
232(24 \cdot 4 \%)\end{array}$ & $\begin{array}{rc}55 & 7 \cdot 4 \%) \\
212 & (28 \cdot 7 \%)\end{array}$ \\
\hline Total & $477(47 \cdot 1 \%)$ & $401(42 \cdot 2 \%)$ & $267(36 \cdot 1 \%)$ \\
\hline
\end{tabular}

Outside Contacts. - A total of 261 patients (144 males, 117 females) were not visited and rarely or never went out; 143 (87 males, 56 females) had no known relatives or friends. The numbers had continued to fall but the proportions had changed little (Table IV).

TABLE IV-Outside Contacts

\begin{tabular}{|c|c|c|c|}
\hline & 1960 & 1964 & 1970 \\
\hline 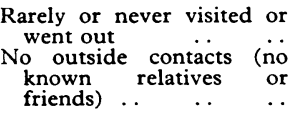 & $\begin{array}{l}344(33.9 \%) \\
201(19 \cdot 8 \%)\end{array}$ & $\begin{array}{l}285(30 \cdot 0 \%) \\
182(19 \cdot 2 \%)\end{array}$ & $261(35 \cdot 3 \%)$ \\
\hline
\end{tabular}

Employment.-The number of patients unemployed continued to fall but the proportion remained the same over the 10 years, though showing a $7 \%$ rise from 1964 (Table V). The proportion at work remained about the same while the number and proportion of those involved in hospital chores showed a continuing fall.

TABLE v-Patients' Employment

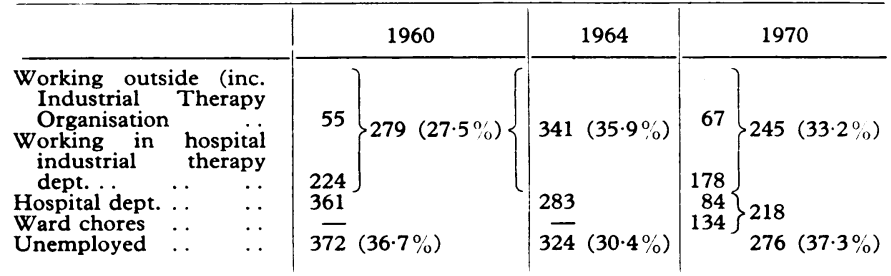

Type of Work Before Admission.-Only 85 patients (54 males, 31 females) had ever held skilled jobs, and 189 (99 males, 90 females) had never been employed. The remainder (465; 190 males, 275 females) were mainly unskilled or selfemployed.

Subnormality.-Altogether 83 patients $(11.2 \%$ of population surveyed) suffered from subnormality, 34 of them $(4.6 \%)$ not showing evidence of psychological illness (Table VI).
TABLE VI-Subnormality

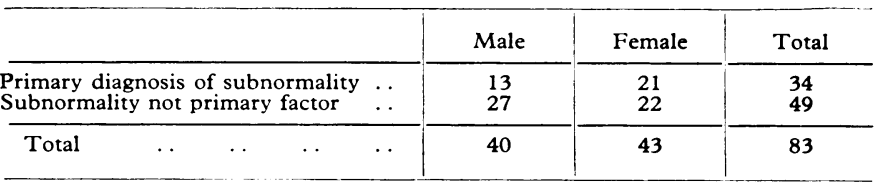

Type of Accommodation Required.-The numbers of patients in need of psychiatric care had diminished, more so in the case of women than men, though the proportion of women requiring geriatric care had risen (Table VII). A large number and a rising proportion still required aftercare accommodation. Of these patients 137 ( 74 males, 63 females) were aged under 65 and 133 (38 males, 95 females) were over 65.

TABLE VII-Type of Accommodation Required

\begin{tabular}{|c|c|c|c|c|c|}
\hline & Year & $\begin{array}{l}\text { Psychiatric } \\
\text { Care }\end{array}$ & $\begin{array}{c}\text { Geriatric } \\
\text { Care }\end{array}$ & Aftercare & Other \\
\hline $\begin{array}{l}\text { Males } \\
\text { Females }\end{array}$ & $\left\{\begin{array}{l}1960 \\
1964 \\
1970 \\
1960 \\
1964 \\
1970\end{array}\right.$ & $\begin{array}{ll}288 & (63 \cdot 7 \%) \\
270 & (62.2 \% \\
207 & (60.1 \%) \\
270 & (48.3 \%) \\
292 & (56.9 \%) \\
173 & (43.7 \%)\end{array}$ & $\begin{array}{ll}21 & (4.6 \%) \\
21 & (4.9 \%) \\
17 & (5 \%) \\
62 & (11.1 \%) \\
52 & (10.1 \%) \\
54 & (13.6 \%)\end{array}$ & $\begin{array}{ll}135 & (29.8 \%) \\
121 & (27.7 \%) \\
112 & (32.7 \%) \\
186 & (33.3 \%) \\
138 & (26.8 \%) \\
158 & (39.9 \%)\end{array}$ & $\begin{aligned} 9 & (2 \%) \\
22 & (5.1 \%) \\
7 & (2 \%) \\
41 & (7.3 \%) \\
32 & (6.2 \%) \\
11 & (3.2 \%)\end{aligned}$ \\
\hline Total & $\left\{\begin{array}{l}1960 \\
1964 \\
1970\end{array}\right.$ & $\begin{array}{ll}558 & (55 \cdot 1 \%) \\
562 & (59 \cdot 2 \%) \\
380 & (51 \cdot 4 \%)\end{array}$ & $\begin{array}{ll}83 & (8.2 \%) \\
73 & (7.7 \%) \\
71 & (9.6 \%)\end{array}$ & $\begin{array}{ll}321 & (31 \cdot 7 \%) \\
259 & (27 \cdot 3 \%) \\
270 & (36.4 \%\end{array}$ & $\begin{array}{ll}50 & (4 \cdot 9 \%) \\
54 & (5 \cdot 8 \%) \\
18 & (2 \cdot 4 \%)\end{array}$ \\
\hline
\end{tabular}

\section{Discussion}

The present survey, the third 12 in 10 years, was undertaken to assess rate of run-down of beds and progress towards the achievement of the goals of the Hospital Plan for England and Wales, ${ }^{3}$ based on the figures of Tooth and Brooke ${ }^{4}$ on which we commented in $1964 .^{2}$ The target figure for Glenside Hospital was set at 800 by 1975 ; this figure was attained early in 1971. Several major factors contributed to thisthe appointment of consultant medical staff with main duties at the hospital, particularly of a doctor with a special interest in psychogeriatrics, together with the further development of industrial therapy and of supporting hotels and houses in the community. Five consultants now work at Glenside, each with a special interest, and the hospital includes an undergraduate teaching unit and two day hospitals, one of which is for psychogeriatric patients. As the number of beds has fallen so the number of admissions has risen rapidly, reaching 1,022 in 1970 .

The age structure of the longer-staying patient continues to shift further towards old age, so that 75 is tending to become the "geriatric" age rather than 65 . The rise in the proportion of patients over 65 to $41.9 \%$ is entirely due to the increased proportion of aged persons among the female population, where $56 \%$ are now over the age of 65 and $16 \%$ are over the age of 80 .

Fewer patients have required to be statutorily detained and the number with a history of criminal acts has fallen. This latter fact may be due to the retirement of a colleague who had a special interest in criminal practice. The sharp drop in numbers of patients who had been in hospital five years or more is related to death and to an active discharge policy for long-stay patients and for recent admissions, together with day-patient developments and continuing development in the community of the Industrial Therapy Organisation ${ }^{5}$ and the Bristol Industrial Therapy Housing Association. Local authority facilities have not increased since 1964.

The number of patients who stayed two to five years (126 in 1970) has not decreased; the proportion rose from $12.3 \%$ to 
$17 \%$ in 10 years. This is suggestive that this group is now faring no better than 10 years ago. Patients who stayed 3 to 24 months fared better, the comparable figures being 150 $(14.6 \%)$ in 1960 and $113(15.3 \%)$ in 1970 .

It is important that the needs of these groups be studied with particular care in planning bed requirements for the future. Hailey, ? in his review of long-stay inpatients, warns that when considering projected figures for bed usage the planner "does not place upon them more reliance than they will bear." Wing ${ }^{8}$ points out that the Department of Health and Social Security estimate of 0.5 psychiatric bed per 1,000 population seems very low and asks that the evidence to support this figure be speedily published. We too believe that the soundness of this prediction should be evaluated openly and critically. If $25 \%$ of beds in psychiatric units in district general hospitals are allocated to long-term patients probably on the evidence of our surveys 0.5 bed per 1,000 population will not be enough.

Assessment of patients' behaviour-a subjective matterindicates that the main problem in social acceptance lies in the field of poor sociability rather than in antisocial behaviour. The small numbers now requiring no nursing care indicate that the problems of discharge will become more difficult. There is, however, a substantial group of patients who are thought to require "minimal nursing care," and with these further progress is possible. The number of patients with no known relatives or friends and who seldom or never go out remains disappointingly high, but it can be partly explained by the fact that almost $88 \%$ of this population is single, widowed, or separated from their spouse and that 143 patients ( 87 males, 56 females) have no known friends.

Employment-wise, industrial therapy within and outside hospital continues to be a major feature of hospital treatment. More day patients attend the hospital industrial departments - a change similar to that which has occurred in the Industrial Therapy Organisation, where the proportion of patients from hospital has gone down while that from the community is on the increase. The large and increasing number of the aged in the hospital is one of the main reasons for the smaller number of employed patients. Earnings in the hospital industrial therapy department, however, have risen by more than $23 \%$ since 1965 in spite of falling numbers. Allowing for inflation this is a considerable achievement, particularly since so many hospital patients (189) had never had any kind of a job before admission and that the vast majority of the rest had held only unskilled jobs.

The problem of the subnormal patient was subjected to more detailed analysis than in previous surveys. This was mainly in response to the Department of Health and Social Security's request ${ }^{9}$ in January 1971 . The figures are not inconsiderable and show that the equivalent of one medium-sized ward is required to house the patients who suffer from subnormality without evidence of psychosis.

The accommodation requirements show once more the unnecessary retention in hospital of patients who do not specifically require hospital care and treatment. The numbers assessed as in need of geriatric care are all the more significant because this assessment was carried out by a physician with a special interest in psychogeriatrics.

Of the patients reviewed in $1970380(51.4 \% ; 207$ male, 173 female) required continuing psychiatric care and treatment, of whom 276 (183 males, 93 females) were under the age of 65 . Of 310 patients aged 65 years and over, $71(9.6 \%)$ were suitable for geriatric hospital care, while 133 (95 females, 38 males) needed supervised aftercare accommodation. All of these could be looked after in accommodation designed for the elderly mentally infirm and about half of this number could live in Part III accommodation if the requirements of this type of accommodation were more liberally interpreted. There were 137 patients ( 74 males, 63 females) under the age of 65 who required aftercare accommodation. A further seven women required unsupervised aftercare accommodation.

The large number and increasing proportion of patients in this category indicate the failure of Mental Health Act legislation to procure the necessary developments. Phillips ${ }^{10}$ showed that local authority hostel development is totally inadequate to cope with this problem, and it is unlikely that other approaches such as boarding out (for example, in Somerset ${ }^{11}$ ) will deal with the situation. Magnus ${ }^{12}$ asserted in 1967 that the criteria for acceptance for aftercare by local authorities have been too exclusive, while the experience of the Bristol Industrial Therapy Housing Association ${ }^{6}$ has demonstrated a need, and has shown that quite a large number of vacancies can be provided in the community even by an organization starting without capital. If the number of patients requiring geriatric care and aftercare in the community could be catered for outside the mental hospital, together with those patients suffering from subnormality without psychosis, then the problem of development within the psychiatric hospital would become much clearer. Overcrowding would have disappeared and one could begin to think in terms of units of accommodation appropriate to patients' needs, together with the development of specialized facilities to back up a developing service centred on a district general hospital. Indeed, if the inappropriate admission of patients suffering from chronic organic brain disease could be prevented it would become possible within five years to think of Glenside as a hospital of about 300 beds fulfilling specialized functions.

"The unpleasant reality"13 suggests that more of the large mental hospitals should close. In our opinion they should all be replaced, but this will not be possible without development of community and hospital services far above anything which seems possible at present. Our previous fears ${ }^{12}$ that psychiatric hospitals may become 20th century workhouses are echoed by Wing ${ }^{8}$ when he indicates the paradox which may ensue from concentrating resources on the development of acute beds in general hospitals in isolation from other problems so that "a relatively good service for the acutely ill would exist side by side with a second-class service or no service at all for the chronic patient." The danger to the psychiatric patient has not passed.

We are grateful to the nursing staff of Glenside Hospital, who by their knowledge and understanding of their patients contributed greatly to the compilation of the facts in this paper.

\section{References} ' Cooper, A. B., and Early, D. F., British Medical fournal, 1961, 1, 1600.
2 Early, D. F., and Magnus, R. V., British fournal of Psychiatry, 1966, $112,595$.

${ }^{3}$ Ministry of Health, Hospital Plan for England and Wales, Cmnd. 1604 London, H.M.S.O., 1962.

- Tooth, G. C., and Brooke, E. M., 1961, Lancet, 2, 710.

${ }^{5}$ Industrial Therapy Organisation (Bristol) Limited, Annual Reports 1960-70.

- Bristol Industrial Therapy Housing Association, Annual Reports 1966-70.

7 Hailey, A. M., Psychological Medicine, 1971, 1, 128.

? Wailey, A. M., Psychological Medicine, 1971, 1, 128.

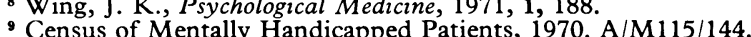

10 Phillips, H. T., Medical Officer, 1966, 115, 85. A/M115/144.

${ }^{11}$ Parry Jones, A., Buchan, A. R., and Beasley, J., Lancet, 1970, 2, 712

12 Magnus, R. V., British fournal of Psychiatry, 1967, 113, 555.

${ }_{13}$ British Medical fournal, 1971, 1, 415. 